\title{
Methodology and principles of assets allocation
}

\author{
V.V. Osadchii ${ }^{1}$, A.L. Zolkin ${ }^{2,}$, O.P. Shevchenko ${ }^{3}$, I.A. Poskryakov ${ }^{4}$ and N.F. Zavialova ${ }^{5}$ \\ ${ }^{1}$ International University of Digital Economy and Technology, Moscow, 121614, Russia \\ ${ }^{2}$ Computer and Information Sciences Department, Povolzhskiy State University of \\ Telecommunications and Informatics, Samara 443010, Russia \\ ${ }^{3}$ Department of Management, Federal State Budgetary Educational Institution of Higher Education \\ "Kuban State Agrarian University named after I.T. Trubilin, Krasnodar 350044, Russia \\ ${ }^{4}$ Department of labor economics and human resources management, Federal State Autonomous \\ Educational Institution for Higher Education Russian Transport university, Obraztsova Street 9, \\ facility 9, Moscow 127994, Russia \\ ${ }^{5}$ Department of transport economic and management, Federal State Autonomous Educational \\ Institution for Higher Education Russian Transport university, Moscow 127994, Russia
}

\begin{abstract}
Every year the number of those wishing to dive in investments is growing at exponential way. In despite of situation in 2020 many people could efficiently use this time, and some of them could even reserve the assets. But now the other challenge is arisen, how should the assets be invested in an effective way using all power of modern financial markets? The slight knowledge intended for experienced people are presented in the most books, articles and manuals. But how the novice investors should manage which do not see the difference between stock and bond, and the "diversification" word ignites panic-driven fear and discourages from development in this area. The material helping every of those wishing to start without fear and doubts the diving in investment from the very beginning is presented in this work. The main classes of assets with which the Wall Street's financial experts work, principles for assets allocation and methods helping to choose the optimal model for profit-risk calculation are described in this article.
\end{abstract}

\section{Introduction}

The beginning of XXI century was not easy for global commons. The series of crisis and economic meltdowns made adjustments to market.

Wars, terrorism and sharp price declines on real estate properties drove the many investors to reconsider their views on assets allocation as well as on investment process in general. The investment strategies which worked early became not only low-profit but "dangerous" from their future application because could zero out all inputs. Now there is a concern of future effective market performance, confidence to it and wish of every investor, especially the novice ones, to understand what next step can help to minimize the risks and not loose in profit [1,2]. Currently the material of this study has the rationale because many novice investors has very poor understanding about those hidden problems

\footnotetext{
* Corresponding author: alzolkin@list.ru
} 
which can be faced if they will manage without clear and appropriately compiled plan. The basic knowledge on assets allocation from profit-risk point of view is described in accessible terms in this work.

\section{Problem statement}

The objective of this research is to study the key methods and principles of assets allocation. Challenges:

1. describe the basic knowledge on assets allocation;

2. identify the basic principles of assets allocation;

3. describe the basic methods of assets allocation.

The research hypothesis is it is expected that study of methods and principles of assets allocation with next using in life of novice investors will allow to build the appropriate and reliable financial strategy which help to allocate the assets efficiently hereby minimizing the risks.

\section{Research questions}

The experience, private knowledge, works of internationally recognized finance experts and business-speakers were used as the methodology base for study in this research. The book publications dedicated for development of methods and principles of assets allocation were used as a base for theoretical research. Analysis, comparison and classification of assets, methods and principles were used as a base of empirical research.

\section{Materials and methods}

The main difference in relation between people and money is the final sum which is needed for every person to feel himself financial free and to have the ability to cover all main debts. In other words, we each are different by manner of living, choosing of career way and opening possibilities which finally form our living principles and standards. And what is good for one, will induce the discomfort and wish of changes for other. The ability to coordinate the current assets and all money flows in future with debts is the important challenge for every novice investor $[3,4,5]$. The development of appropriate financial planning and normal investment policy will be required here.

Investment policy is represented by document where the plan of asset development and management is recorded. Plan has brief and understandable form. This plan can be compiled itself or with assistance professional consultants. However, not every is ready to give their earned money to unknown people without guarantee of successful result. Therefore, all main classes of assets, their principles and methods of allocation to develop its own sufficient investment policy are reviewed in detail in this research.

\section{Results}

So, let's define the strategies with investors behavior on financial markets and assets allocation. There three types of investment behavior:

1) strategic or passive portfolio investments;

2) dynamic and tactical;

3) selection of appropriate time for actions on market.

Strategic allocation has the second name "buy and hold". This type of strategy is based on selection of optimal types of assets and tools which are stored in portfolio of investor for 
long time. The choosing the one of the type of assets should not depend on economic market situation, subject views on TV from fail experts on asset allocation. After choosing the appropriate assets and formation of portfolio it is important to review it sometimes and make the corrections if it is necessary. The correction is especially needed when there are global changes in investor's private life.

The second type of allocation is tactical that includes the active correction of portfolio depending on actual market forecasts. The economy with stocks and bonds is analyzed here, for example, annual and quarterly reports of emitter companies. Based on this analyses, the conclusion on which stocks should act better, and which ones are worse is made [6].

The third type of allocation is also called as market-timing. This is historically the oldest type of strategy. It is simply called as speculation strategy. When the people try to win the market by choosing the rime of operation. The principle of "buy cheaper, sell more expensive" works here. This is the peak way of tactical allocation. This strategy is suited for those market participants who consider that can be always in trend of all market changes and can quickly answer on this.

The second and the third types of strategy are presented themselves as «honey-trap» for non-experienced investors. According to Eugene Fama's hypothesis of effective market the market is effective depending on information in case of its immediate effect on market price of assets. And if the markets are effective, the receiving of profit which is higher than market one is not possible both with technician or fundamental analysis. It is possible to win, guess, receive the profit, and to receive the negative earnings later and loose the earned earlier. It is possible to receive the short period randomized speculative profit on effective market but it is not possible on regular manner for long time period. The best option is the first type. The appropriate selected portfolio investments which include the various different classes of assets supporting for long time period give the highest results and are the guarantee of success $[7,8]$.

Regardless of chosen strategy every investor creates his own unique investment portfolio which meets his financial objectives and level of risk.

Assets allocation is the subject decision about dividing of investment portfolio on different classed of assets with the aim to maximize the achievement of financial objectives with minimal risks. There are three factors effecting on assets allocation:

1. objective:

- the financial objective, its price and time period should be clearly justified for assets allocation;

- to define the month amount of money for investment;

- the hypothesis of escalation level and profit should be based on real data;

- any financial objective should have the deadline. In other case the achievement of objective will be not possible;

- time horizon. This is the number of months or years during which the investor will invest his money to achieve the objective. Those who chose the long period strategy of investment will be in more comfortable and safe position purchasing the assets with high risk because there is enough time to pass the economic cycles.

\section{2. risk tolerance;}

The ability of investor to save the cold brains observing now the loosing the price of purchased investments with exchange to high profit in future.

The investors who are very stable to risks are ready to risk and lose the investments but in case of "win" they will have the maximum profit. Conservative investors, as the rule, have low level of risk tolerance. The stability and assurance that investments will be covered are very important for them, therefore, they choose the assets with low profit. 
3.the finance situation at this moment. To speak simply, assets allocation is assumed the choosing of asset class and such amount of money which is required for purchase each of them.

Asset classes:

1) stocks;

Stocks give the high profit but, at the same time, have the very high risk. If the novice investor plans to invest for long time with the aim to earn good money in future, the stocks specifically should be the main part of investment portfolio. However, the volatility should be taken into account because it is very severe, especially, for investments for short time. If the company operates effective, it can pay to its stock-holders the profit as dividends or to repeat the investment of all earned profit to business back what automatically lead to increasing the price of stocks [9]. If the company have problems, the final sum of all invested money might be go down to zero.

2) bonds;

They give the medium profit. The risks are also medium. Bonds create the stable money flow and form potential for money growth. According to money market the profit from bonds is significantly higher. It is suitable for those investors who plan to invest for short, medium and long periods of time. As the volatility in stocks is high, not only the stocks but and the bonds should be included in investment portfolio. They balance the market movement.

3) real estate property;

This type of assets presents to investor the various options of money investments. He can choose the living building, touristic, commercial and other different objects of infrastructure. It is suitable for investments for medium and long periods of time. As a rule, for 5 years and more.

4) money market tools.

Bank accounts, deposit certificates and various funds of money market are included here. This class of assets has the low profit and extremely low risk. This type of assets is actual for short period investments, till three years. The main risk for choosing this class is the escalation. Therefore, money should be stored in hard currency not in Rubles.

\section{Principles of assets allocation}

It is important to committee to three following principles during assets allocation to portfolio:

- the inputs should be safe;

- the investor should receive the profit regularly;

- the prompt realization, i.e. marketability.

\section{Findings}

The main challenge in asset allocation is to find the balance between risks, profit and combination of different assets. There are three basic principles of asset allocation to portfolio:

I. conservative;

Comparison between reliable and risk assets. Balance is maintained by such way when potential negative earnings from risk assets are more likely covered with profit from reliable ones.

II. diversification; 
This is the main principle for asset allocation. The old idiom "Do not put all eggs in one basket" is used in the basis of this principle. In other words, it is important to aim not to invest all money in one class of assets nevertheless of its profitableness. This principle mitigates the risk regarding to the fact that small-scale profits on one class will be covered with higher profits in other classes. The risk mitigation is happened because of adding the assets from different sectors in investment portfolio which are not connected. In case of enough amount of money sector and regional diversification can be performed. Are principle is assumed the excluding imbalance in assets acquire in one sector.

The regional diversification has the same exception as the sector one.

III. optimal marketability.

This principle consists in maintenance of part of assets in portfolio that to be able "to wrap up" a deal with high profitability or complete the investor's requirements in money. The experience shows that investor should have some part with enough marketability within his assets. It will help to be more flexible under conditions of rapidly changing market environment.

\section{Methods of assets allocation}

The investors faced with the problem of assets allocation a long time ago. But in response to American economists the methods which still help investors to allocate their assets were developed.

I. Markowitz model. This method is based on choosing the optimal set of assets according to profit-risk values. In other words, combination of assets in portfolio gives its the new characteristics which are better in profit and in combination of risk/profit [10]. Markowitz gave mathematical methods for decision making, and, at the same time, showed that it is very important to add such assets in portfolio which have the minimum correlation with each other, i.e. proceed differently, independently from each other. The using of this methods includes three parameters:

1) level of profit and risks;

2) analysis of coefficient of association such parameters as profit from two assets;

3) level of profit and risk of investment portfolio itself.

II. Sharpe model. It calls also the index model. Its method assumes the correlation between potential profit from assets and potential profit from market itself. Today this method is used for risk calculation in case of big amount of asset investment which are a great weight of whole market. The method of linear regression analysis is the basis of this model.

The difference between of Sharpe and Markowitz models is that Sharpe analyses the correlation of profit from a single asset with total market profit, and Markowitz studied the connection of asset profit with each other.

III. Equated price model. The objective of this method is the application of price difference on assets of the same or similar type on different markets to receive a profit. This method is performed as mitigate element for effective market development. Risk factors, e.g. escalation, and economic development are the parameters of this model. The profit depends on various factors in this model. The more asset reacts on the changes of one of the factor, the more its profit.

\section{Discussion}


People wish to set their own investment portfolio says about market readiness. However, a few people come to its setting as to complicated financial object which has certain specific and its own aspects. Diving in this area is possible only if you have already the free capital and you are ready invest for a long term and agree to moderate income.

\section{Conclusion}

Therefore, there is no common strategy or method on assets allocation that is right and applicable in all situations within financial status and risk tolerance. For diving in investment studying it is important to obtain the primary knowledge which will help to understand the nature of all market processes. The main challenge is to correctly allocate the assets to make maximum profit in future. It is important to find a balance between making the profit and risks.

\section{References}

1. R. Ferry, All about assets allocation (2020)

2. R. Gandapas, E. Dubinsky, Prosperity manage the money or money will manage you (2020)

3. F. Delfani, H. Samanipour, H. Beiki, A. Yumashev, E. Akhmetshin, A robust fuzzy optimisation for a multi-objective pharmaceutical supply chain network design problem considering reliability and delivery time, International Journal of Systems Science: Operations and Logistics, 1-25 (2020). Access mode: https://doi.org/10.1080/23302674.2020.1862936

4. T. A. Lachinina, M. S.Chistyakov, Methods and technologies of innovative marketing: management and financial aspects, III International scientific-practical conference "Economics and management of enterprises, industries, complexes in the context of innovative development.", 43-50 (2018)

5. A. L. Zolkin, T. G. Aygumov, A. I. Pakhomova, V. V. Bobkov, Research of modern opportunities for obtaining the grant support for innovative projects financing, IOP Conference Series: Earth and Environmental Science. Krasnoyarsk Science and Technology City Hall, 677, 22032 (2021). Access mode: https://iopscience.iop.org/article/10.1088/1755-1315/677/2/022032/pdf

6. E. A. Lavrov, A. L. Zolkin, T. G. Aygumov, M. S. Chistyakov, I. V. Akhmetov, Analysis of information security issues in corporate computer networks, IOP Conference Series: Materials Science and Engineering. Krasnoyarsk Science and Technology City Hall, 1047, 12117 (2021). Access mode: https://iopscience.iop.org/article/10.1088/1757-899X/1047/1/012117

7. E. Lavrov, Development of models for the formalized description of modular elearning systems for the problems on providing ergonomic quality of human-computer interaction, Eastern-European Journal of Enterprise Technologies. Ser. "Information technology", 2 (86), 4-13 (2017). Access mode: https://doi.org/10.15587/17294061.2017.97718

8. E. A. Lavrov, P. I. Paderno, A. A. Volosiuk, N. B. Pasko, V. I. Kyzenko, Automation of Functional Reliability Evaluation for Critical Human-Machine Control Systems, Proceedings of 2019 3rd International Conference on Control in Technical Systems, (CTS), 144-147 (2019). Access mode: https://doi.org/10.1109/CTS48763.2019.8973294 
9. A. I. Abdryashitova, M. S. Chistyakov, "Internet of Things" as a factor in the development of the digital economy and marketing communications, 245 "Transformation of the economy: analysis of problems and search for solutions": materials of the All-Russian (with international participation) scientific and practical conference dedicated to the 60th anniversary of the BTI AltSTU, 1, 194 (2019).

10. A. Vlasyuk, V. Zhukovskyy, N. Zhukovska, S. Shatnyi, Parallel Computing optimization of Two- Dimensional Mathematical Modeling of Contaminant Migration in Catalytic Porous Media, 2020 10th International Conference on Advanced Computer Information Technologies (ACIT), 23-28 (2020) 